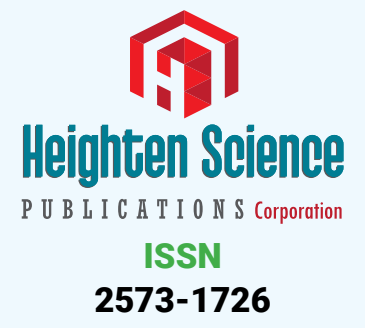

*Address for Correspondence: Andrew Hague BA (Hons), Dip M, Professor of Advanced Medicine, Honorary Fellow of the International Academy of Medical Sciences, President of CellSonic Limited, UK,

Email: cellsonic.beauty@gmail.com

Submitted: 14 June 2018

Approved: 02 July 2018

Published: 03 July 2018

Copyright: @2018 Hague A. This is an open access article distributed under the Creative Commons Attribution License, which permits unrestricted use, distribution, and reproduction in any medium, provided the original work is properly cited.
Letter to Editor

\section{The Exercise continuum and the role of Doctors}

\author{
Andrew Hague* \\ BA (Hons), Dip M, Professor of Advanced Medicine, Honorary Fellow of the International \\ Academy of Medical Sciences, President of CellSonic Limited, UK
}

\section{Introduction}

Everyone can be placed somewhere on an exercise continuum with the idle at one end and the hyperactive at the other. At both extremes, health suffers. Exercise is essential to health and managing it is the responsibility of individuals but few know what they should do. Doctors seldom teach how to be healthy and act only when repair is needed.

\section{The Idle}

In the oceans, lakes and rivers are creatures that stay in one place and water flows over them bringing food to their open mouths and removing waste from the opposite end of their bodies. Of all land animals, humans are the only creatures able to exist by the same idle method. The human brain can contrive a situation in which other humans care for idle ones and this is not about looking after a patient in bed, it is feeding an idle person who commands others. That image, perhaps of ancient kings, is seen by many to represent ultimate ambition; servants supplying all needs. The reality is that the idle one is the one that suffers and those scurrying around have more benefits.

These days, physical inactivity is available to all, rich and poor and some of the poor appear to love it. Getting food has become no more arduous than opening a packet. Ordering and paying for it is done by pressing buttons on a smart phone and getting the money in the first place is in some countries only a matter of getting state aid on the grounds of unemployment or being unable to work. The more idle they are, the less they are able to work. The consequences are obesity, diabetes and heart disease. Muscles weaken and joints are unable to carry the added weight. Generally, idleness is accompanied by little mental stimulation which leads to further decay of the body. Doctors are then asked to make repairs. In go the drugs, up go the pharmaceutical profits and up go the costs to insurers and governments. Should the doctor take the smart phone away, ban them from television and send them swimming three times a day because swimming is less damaging to fat limbs than walking and to run is impossible? Such hardship would help the patient and in some rare cases it is being done. Usually they get drugs and a suggestion that they should exercise but no enforcement. This is the situation in the prosperous countries in recent years.

\section{The hyperactive}

In racing sports, they talk of going through the pain barrier. The margin of safety is considerable. Grin and bear it and you will win. By that means, it was not always the strongest who won but the person who could tolerate most suffering. When drugs became available, the pain barrier ceased to be a barrier and the body lost its protection. The determination to win would expose the body to excess stress that could be fatal (Figure 1). 


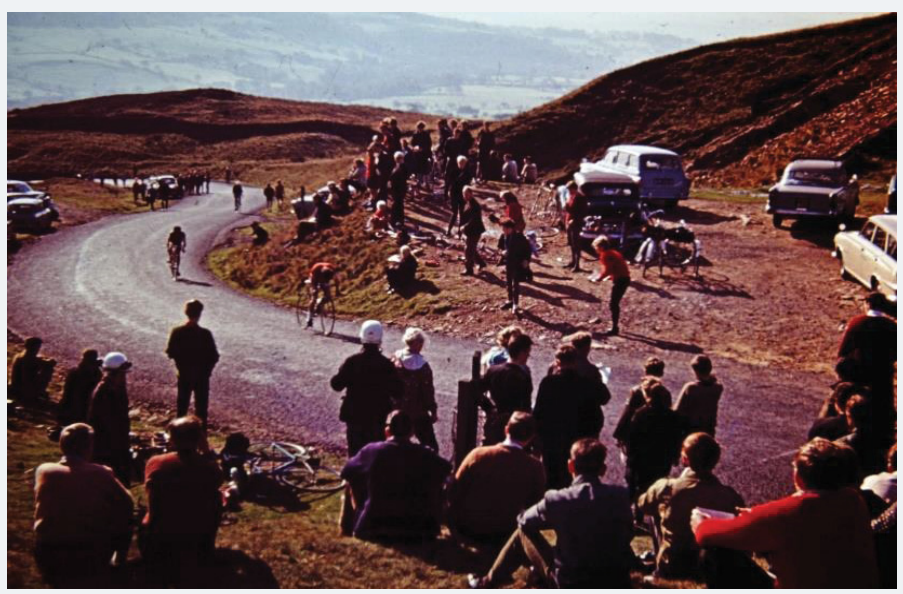

Figure 1: Repartition of patients according to cardiovascular risk factors.

I took this photograph of a bicycle hill climb in 1965. Almost certainly no performance enhancing drugs were used. At the finish line, all the competitors were gasping for breath and some lay on their back to recover but they were up again in a few minutes grinning and eager to find out their time. The winner I knew well back in those days and he went on to become the National Hill Climb Champion. He was only a year older than me and, from what I have been able to find out, he died some years ago of a strange illness. He had suffered a crash in a race and had never properly recovered. This, as I see it, is a danger. He had pushed himself too far, not just in physical effort but by taking chances. It was a risk he would not ordinarily have taken but, in a race, where everything is about winning it becomes combat.

The drugs scandals at the Olympic games and in the Tour de France cycle race are now headline news. That competitors will sacrifice their lives for the vanity of winning shows the danger of sport at this level.

Amongst amateurs, dangers abound. There are combat sports that were encouraged because they prepare soldiers for battle. With less hand to hand fighting in modern armies and more alternatives in schools that are threatened by lawyers there is less boxing but rugby is still popular especially in fee-paying schools. A young boy's father will tell him that the rough treatment in a game of rugby will make a man of him. If the boy is stocky enough and determined, it is very likely he will have a life changing injury before he is thirty. Physiotherapists and orthopaedic surgeons specialising in joint replacements are grateful to football, squash and tennis for the business it brings. Footballers get kicked as well as adding pressure to their knees and hips. Racquet games twist the knees more violently than straightforward running with the result that a titanium implant is offered as the easy repair. The fact that a revision (another replacement) will be needed ten to fifteen years hence is seldom mentioned.

At the extremities of all sports there are dangers even in those that are dangeravoidant. Rock climbing is all about fall prevention until the glory of not using a rope takes over and then there is no back up. Mountaineering is safe until risk taking becomes more attractive than the scenery and the threats of bad weather, an avalanche or thaw (the ice giving way) are pushed to one side believing that these hazards have been overcome before. Confidence leads to invincibility, a concept that has never been proven.

Over confidence is as much a danger as depression. The role of exercise in combatting depression with the suicides and anger that arise are seldom appreciated. Mental health benefits from exercise as much if not more than bodily health.

There are many activities classed as sports that do not involve muscles and cause damage to the participants and even more so to spectators. Motor racing is a major 
culprit. Deaths on the track are less than they used to be but they instil a culture of speed which on the public road will kill. It was often commented years ago when people went to the cinema that after a James Bond film the cars were hurtling away a break neck speeds with the drivers inspired by what had enthralled them half an hour before. Motor racing is nonsense. The winner is not the most skilful but the one prepared to take most risk. Is that meritous? It is not even a sport.

Shooting must be equally condemned. Just as the ancient Greeks may have delighted in wrestling and the Romans in gladiator fights, those sports gave way to fencing and when those weapons were superseded by guns it was shooting that was applauded. To aim, it is necessary to be fit, so the argument goes, so that one can hold one's breath when firing to keep the gun steady as one breaths. Does that compare with the fitness of a swimmer or any athlete? When the target for shooting is an innocent wild animal or bird, the claim that this is a sport is hard to sustain.

It is a fact that most people are impressionable; they are followers and do not question those they admire. This gives role models a responsibility many of them do not understand. A star footballer is seldom an intellectual. From being groomed at school to being paid to play the game, he has learned only that what he does is right; it must be because he is paid a lot to do it and whatever he does must be right. He has a licence to do anything because at the extreme end of the exercise continuum he excels. Brawn beats brain and entertainment damages a thoughtless majority. Doctors are left to pick up the pieces. Could they have advised so that the damage is avoided?

The importance of exercise

Between the extremes of immobility and hyper-activity is where we should be but where is it? A good observation is a report on cycling to and from work:

https://www.forbes.com/sites/kevinmurnane/2017/04/25/new-research-indicatescycling-to-work-has-extraordinary-health-benefits/\#553e5b233e62

Kevin Murnane writes: The effects of walking and cycling were measured by comparing them with the Non-active mode of transport. Cycling to work was associated with very large health benefits. Commuters who cycled to work had a $41 \%$ lower risk of dying from all causes than people who drove or took public transport. They also had a $46 \%$ lower risk of developing and a 52\% lower risk of dying from cardiovascular disease, and a $45 \%$ lower risk of developing and a $40 \%$ lower risk of dying from cancer.

This is a study of ordinary people doing what everyone does, getting around as easily as possible. When it involves exercise, there are great benefits - listed in the article:

http://www.cyclingweekly.com/news/latest-news/benefits-of-cycling-334144

1. Cycling makes you happy

2. You lose weight

3. And build muscle

4. Without worrying about over eating

5. Good for the lungs

6. Cuts heart disease and risk of cancer

7. Less damage to joints

8. Saves time and money

9. Mental skill of route finding 
10. Better sex

11. Better sleep

12. More brain power

13. Improved reactions and responses

14. Better immune system

15. More friends

Each one of the above would be a medical breakthrough. To get the lot for free is astounding and true.

In richer countries in the last decade cycling has become more popular and is said to be the new golf. For those who have always cycled, it is flattering to be recognised as sensible and not shouted off the road as used to happen. When the scientists investigate, they explain what to the cyclist is obvious:

http://www.cyclingweekly.com/news/cycling-keeps-immune-system-strong-bodyfat-levels-low-old-age-study-finds-372227

Michelle Arthurs-Brennan reports that a study followed 125 long-distance cyclists. The riders are now all in their 80 s but their immune system function is similar to that of 20-year-olds.

The research, published in the Aging Cell journal, showed that the ageing cyclists produced the same number of T-cells-which help the immune system respond to new infections - as adults still in their 20s, and a separate study revealed that cyclists didn't lose muscle mass, strength, or gain body fat in the same way as non-cyclists.

Co-author of the report, Prof Norman Lazarus of King's College London is 82 himself; he told the $B B C$ : "If exercise was a pill, everyone would be taking it. It has wide-ranging benefits for the body, the mind, for our muscles and our immune system."

In parallel, the same journalist presents a report on the sex lives of female cyclists:

http://www.cyclingweekly.com/news/latest-news/cycling-results-better-sexlives-women-study-shows-373243

Saddle discomfort is mentioned and the solution is a well-made lady's saddle of which there are many on the market. They have a slot along the top to avoid pressure on the genitalia. Usually the nose of the saddle is angled down for a lady whereas a man will have the saddle horizontal. Every woman should be able to ride comfortably. If you have a problem, a good bike shop will help you. (BioFlex O-Zone Gel Womens Saddle-Black).

The reports about Robert Marchand are incredible. He is the first of many in his category.

http://www.cyclingweekly.com/news/latest-news/106-year-old-hour-record-holderrobert-marchand-announces-retirement-from-competitive-cycling-365196

One year after setting a new Hour Record for his age category, centenarian cyclist Robert Marchand has decided to hang up his wheels and retire from competitive riding at the grand old age of 106. A multiple record holder for age-group events, Marchand has now been advised not to take on any further competitive events on medical grounds. He can continue cycling but should stop racing. Read the report and note that there is nothing extraordinary about Robert other than he is doing what others half his age could not do. If he can do it, others can. 
Born in Amiens in 1911, Marchand started riding at the age of 14, but gave up the sport only to return to cycling in 1978 aged 67 . Since then he has maintained a daily routine of riding and stretching, eating plenty of vegetables and little meat, not smoking, and generally avoiding alcohol.

Here is a report on a study of aging published on $6^{\text {th }}$ January 2015 in The Journal of Physiology:

http://road.cc/content/news/139982-cycling-fights-ageing-process-say-researchers

Emeritus Professor Norman Lazarus, a member of the King's team and also a cyclist, said: "Inevitably, our bodies will experience some decline with age, but staying physically active can buy you extra years of function compared to sedentary people. "Cycling not only keeps you mentally alert but requires the vigorous use of many of the body's key systems, such as your muscles, heart and lungs which you need for maintaining health and for reducing the risks associated with numerous diseases."

On the $8^{\text {th }}$ March 2018, Prof Lazarus's team published another study in Aging Cell published by the Anatomical Society and John Wiley \& Sons Ltd. and appears to be a similar group of people, maybe the same.

https://onlinelibrary.wiley.com/doi/full/10.1111/acel.1275 Study confirming old cyclists same as healthy young.

The benefits of exercise all one's life have always been known. The biological data is now measured in the Aging Cell report of the study by Birmingham University.

http://www.talkhealthpartnership.com/blog/2015/10/the-health-benefits-ofcycling-in-old-age-2/

Dr Ross Pollock, who led the team of scientists from King's College London, warned that most of us are inactive, which causes 'physiological problems at any age'.

http://www.dailymail.co.uk/health/article-2898123/The-secret-staying-youngbike-Tests-cyclists-seventies-physically-younger-people-age.html

Study of cyclists found they were physically younger than most their age

Underwent extensive tests of their heart, lungs and exercise capacity

Researchers found they had muscle strength similar to younger people

Say it proves cycling keeps the body and the mind staying young Aging and Physical Performance is explained in the link:

http://cptips.com/age.htm fitness and aging

\section{Mind and body}

If the articles referred to above suggest that all that is needed to get all the benefits is to move muscle, think again. The mind and body are inseparable. In a paper published last year on The Body's Operating System, I discussed the effect of mind on body. The interaction is also body on mind.

The Birmingham and Kings Studies accurately report the biological effects of exercise. It should be obvious that the same effect will apply to runners, walkers, swimmers and all active people. In these studies, cyclists formed a convenient group that could be identified and measured. Kevin Murnane's article listing 15 benefits is correct. This includes mental health. One cannot cycle without thinking. The machine has to be maintained. It can fail when you are miles from home and you have to fix it. Problem solving is where our brain excels. It distinguishes us from other animals and has got us to the stage where we can disrupt our environment; to solve the problems we have created (Figure 2). 


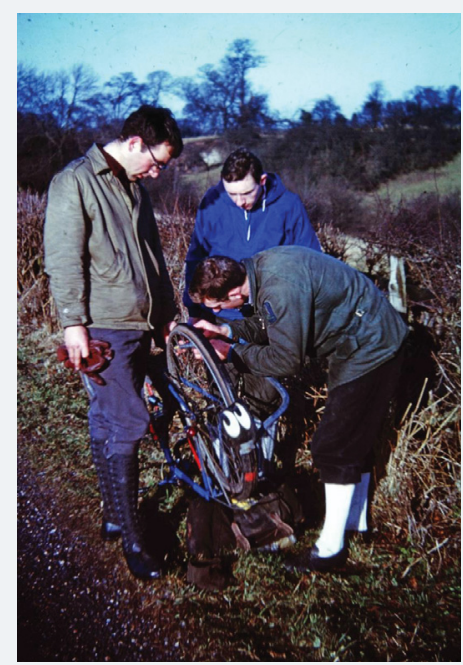

Figure 2:

The man repairing a puncture became the British National Hill Climb Champion. With modern tyres and less glass on the road, punctures are not as common as they were. We used to always repair the puncture, not just fit a new tube, and competed to see how many patches were on a tube before it was eventually discarded. You will see that his friends are there to tell him what to do even though he would do better without their distraction. This is social interaction at its best. The group broke up as members dispersed to study and work, married and, in some cases, died. I am still cycling and, if this article makes sense to you, am still fit and cognitively active. The BirminghamKings studies required the old cyclists to be able to ride at ten miles an hour for over six hours. Believe it our not, that is very easy. Normal cycling speed is $14 \mathrm{mph}$ and a club (chain gang) can be doing evens (20 mph or more). For $10 \mathrm{mph}$ to make the difference between being as fit as a person 40 years younger is very interesting.

This shows that the discovery is not that exercise helps, it is that no exercise is damaging. To exercise always all one's life is normal. To refer to the cyclists as a remarkable minority is to forget what we are, animals born to forage and hunt from dawn to dusk. To feed, we had to exert. When people are astounded that I can ride a hundred miles $(160 \mathrm{~km})$ a day, I tell them it is only ten miles an hour for ten hours. If there was more time available, I would be able to cover longer distances. It is not a matter of strength. A normal person is well capable of these distances. The pity is, they don't know it. Nevertheless, more people are discovering they have hidden talent. Often a bicycle is daunting and they do not live where there are quiet roads. They make go walking, Scottish dancing, swimming or just flogging themselves in the gym.

\section{Resistance}

Look at again at the photo of the puncture being repaired. This was before most wheels had quick release hubs. He has taken the tube out of the cover without removing the wheel to avoid getting his hands dirty on the oily chain but he is still going to end up with the grime of the road and aluminium oxide from the rim on his hands and nowhere to wash them. The simple answer is to peel and eat an orange. We were never ill. In the summer of 1966 I cycled from Graz to Athens on unsurfaced roads through the Balkans averaging over a hundred miles a day. There were no plastic bottles of water for sale in shops back then. The water bottle carried in a cage on the bike frame was topped up at roadside wells and pumps. I never had diarrhoea and I drank a lot cycling in the heat through Greece. Nowadays, our exposure to germs is no less but our resistance is far less. Go on an airline flight for a few hours and breath the air expelled by your fellow passengers and be prepared for a sniffling cold for a few days afterwards. These are serious dangers. 
Exercise in the open air, away from cities and pollution and your immune system improves not just from exercise but from the simple relationship with your environment, a relationship with which we have evolved. India has a campaign for indoor toilets to be flushed clean by water and proper sewage management. Outdoor defecation that had served for centuries became impractical as population density increased and privacy, especially for the girls and women, became difficult. They are moving to a modern system in which chemicals will certainly be used to solve one problem and cause others. The immune systems will adapt maintained by exercise, sleep, diet and a balanced approach to hygiene. We can be too careful.

\section{Sunshine}

Use of gyms is growing and is to be encouraged. For a traditionalist and outdoors man like me, a gym is hard work and uninspiring. In some climates, extremes of hot and cold, it can be the only option. In temperate climates the smell of fresh air, birds singing and wind in the face is pleasure. What the scientists investigating the improvement to the immune system did not record is the vitamin D from sunlight. You don't get it in a gym and the modern practice of protecting the skin from the sun reduces the essential vitamin intake. Sunglasses are worn too often. There appears to be a belief that they protect the eyes. If that were true, I should be blind by now. Bright sunshine tells the skin to beware, it changes and adds protection. People outdoors all the time seldom have the skin cancers that attack those exposed infrequently to unfiltered sun. In high altitude Switzerland and under the thin skies of New Zealand and the southern hemisphere, the conditions are dangerous and protection is essential. Under the haze of The Gulf, sunburn is less a risk.

\section{Diet and drinks}

The old cyclists who have cycled almost all their lives learned what to eat and what to avoid. Very few smoked and that made them outcasts in the 1950s and 60s when the majority of people smoked. You did not need to be a scientist to see that the smoker had not got the puff to pedal. In other words, his lungs were being damaged by smoke. In those days, and I remember them well, almost all doctors smoked. In their ignorance, they gave their patients bad advice.

Food was frequently discussed. We had large appetites. There was more organic food fifty years ago and it was fresher because transport was less efficient than today; food had to be grown locally. Knowing what was best to eat was understood by all and we worked it out empirically. One rider worked as a window cleaner during the week and cycled at the weekend so he was physically active outdoors every day in all weathers. He was our advisor and paid little attention to books. His knowledge came from experience. He never added sugar to his drinks or salt to his food and his explanation made sense to all of us. There was enough carbohydrate in a balanced diet and too much sugar meant too little roughage. Bran and the bike kept him regular. The amount of salt added to bread was more than enough in a temperate climate. Maybe in hot weather when sweating increased the water through-put there is a case for additional salt and more fluids but for the mileage we were doing, about 80 miles on a Sunday run, no additives were needed.

We learned to not be on the road after 10 o'clock at night because the drinkers would be driving away from the pubs drunk. It was not illegal to be drunk driving a car. Indeed, when there was a crash, the defence was that the alcohol made the driver incapable so it was only an accident, not deliberate bad driving. If the driver was incapable, he could not be blamed. Eventually this nonsense led to laws banning drivers from drinking alcohol and there seems to be a recent understanding amongst the general population that alcohol damages health. Cyclists knew it many years ago and by avoiding alcohol they have maintained good health. People have to be told. Is that the duty of doctors? 


\section{Resilience}

Whether you are on a mountain ridge in the mist or miles from anywhere on a bicycle, you have only yourself to depend on. You may have companions and they look to you for leadership. You have no choice but to be resilient and carry on, map reading, apportioning your energy, not taking risks. It is all about survival. Move then to a city job and your mental attitude goes with you. Exercise maintained your health mentally and bodily.

\section{The role of doctors}

Clinical evidence that the minority group of old cyclists have an immune system comparable to people in their twenties is proof that the majority of people are in poor health because they do not exercise. If a doctor's duty is to improve people's health, then the doctor has to tell them to exercise and say it before the deterioration goes too far. On the other hand, if a doctor is there only to repair the damage however caused, the doctor can let people make mistakes through ignorance and this will keep the doctor busy and prosperous. Do we not argue that in an ideal world there need be no police? By the same reasoning, doctors should not be needed if people live properly.

Has science got us to the stage where all illness is a mistake? Humans live and work in communities with many specialising thanks to their education. Theoretically we can prevent all illness and injury by education, control and prevention. For example, from the earliest age, teach and practice the benefits of exercise. Avoid the dangers of extremes. Control individuals by implanted chips so that everyone is answerable to an artificial intelligence central computer thereby eliminating the benefits of crime and war (and I would resist this being done to me and demand that it be done to others, such is hypocrisy and was well foretold in Brave New World by Aldous Huxley and 1984 by George Orwell). Ensure that the makers of pharmaceuticals and machines serve the majority in the world and not just the rich. Ebola can be controlled. Cancer is avoidable.

Guidance on these policies can only be given by those who understand the body and mind and they are doctors. Now is the time for doctors to work towards making themselves redundant. I am sure that will never happen but it ought to be an objective. The police do little to prevent crime. They advise people to lock their doors but do nothing to change the motivation of potential burglars other than apply threats of punishment. Similarly, doctors prescribe drugs on top of drugs without getting to the source of a patient's problem. People respond to carrot, not stick.

The evidence is clear. Most people can be maintained in good health by simply changing their lifestyle so that they exercise as much as their bodies have evolved to do. You are a doctor so tell your patient the blunt truth and when you say to them you don't want to see them again, you mean it in the friendliest way. 